Symposium on the Mechanism of HDS/HDN Reactions

Presented before the Division of Petroleum Chemisty, Inc.

206th National Meeting, American Chemical Society

Chicago, IL, August 22 - 27, 1993

\title{
Aniline Hydrogenolysis on the Pt(111) Single Crystal Surface: Mechanisms for C-N Bond Activation
}

\author{
Sean X. Huang, Daniel A. Fischer" and John L. Gland \\ Department of Chemistry \\ The University of Michigan \\ Ann Arbor, Ml 48109
}

*Materials Departinent

NIST

Gaithersburg, MD 20899

\section{INTRODUCTION}

Hydrogenolysis of $\mathrm{C}-\mathrm{N}$ bond on transition metals is a crucial step in hydrodenitrogenation (HDN) reactions. Despite the overall complexity of HDN processes, the details of important surface reactions can be characterized using model reactions of organonitrogen compounds on single crystal model catalysts. The structure and reactivity of well characterized aniline monolayers on the Pt(111) surface both in vacuum and in the presence of hydrogen is discussed here. Adsorption and reactions of aniline were studied by Gland and Somorjai on the $\mathrm{Pt}(111)$ and $\mathrm{Pt}(100)$ surfaces (1), and more recently by Benziger's group on the $\mathrm{Ni}(111)$ and $\mathrm{Ni}(100)$ surfaces (2). On both Pt and Ni surfaces, aniline $\pi$ bonds through the aromatic ring with its ring parallel to the substrate surface.

\section{DISCUSSION}

A combination of temperature programmed reaction spectroscopy (TPRS) and near edge X-ray absorption fine structure (NEAXFS) have been used to characterize adsorption and hydrogenolysis of adsorbed aniline on the Pt(111) surface. These experiments were performed in an UHV end station on U-1 beamline at National Synchrotron Light Source. The UHV system, described in detail elsewhere previously (3), is equipped with facilitics for NEXAFS measure ments using both electron yield and fluorescence yicld detection low-energy electron diffraction (LEED), Auger electron spectroscopy, and multiple mass TPRS. The symmetry of the surface was verified using LEED, while surface cleanliness was verified with Auger. Aniline (99\%) was obtained from Aldrich® and purified by freeze-pump-thaw cycles. Reference NEXAFS spectra were recorded for solid multilayers of aniline. A saturated monolayer was prepared by briefly annealing the multilayer to $210 \mathrm{~K}$. The NEXAFS spectra are normalized to the carbon continuum edge jump to facilitate quantitative comparison. The photon energy reported here were calibrated against the $\mathrm{CO} / \mathrm{Pt}(111) \pi *$ resonance.

Following aniline adsorption on the clean $\mathrm{Pt}(111)$ surface at $95 \mathrm{~K}$, molecular desorption from the multilayer occurred at $200 \mathrm{~K}$. Molecular desorption from the monolayer $\alpha c$ curred at $240 \mathrm{~K}$ (Figure 1). No significant aniline decomposition was observed by NEXAFS below $250 \mathrm{~K}$, thus molecular aniline must remain intact up to $250 \mathrm{~K}$, the temperature where monolayer aniline desorbs. Large hydrogen peaks are observed at $350 \mathrm{~K}$ and $470 \mathrm{~K}$, indicating that partial aniline dehydrogenation is occurring with increasing tempcrature. As successive desorption of phenyl hydrogens continues above $500 \mathrm{~K}$, several unresolved hydrogen peaks were observed.

Hydrogenolysis of aniline by adsorbed hydrogen from aniline dehydrogenation yields a small benzene peak at $400 \mathrm{~K}$, and an ammonia peak at $500 \mathrm{~K}$. The yield of ammonia from a monolayer coverage of aniline increases substantially as the amount of coadsorbed hydrogen increases. In the presence of $1.5 \mathrm{~L}$ post-adsorbed hydrogen, the yield of ammonia increased almost fivefold as indicated by the integrated ammonia areas in the 400 to $900 \mathrm{~K}$ temperature range (see middle spectra Figure 1). The structure and bonding of the species responsible for these hydrogenolysis reactions were examined both in vacuum and in hydrogen using NEXAFS.

The NEXAFS spectrum of multilayer aniline (Figure 2) provides a reference spectrum with good signal-to-noise for resonance identification and assignment (Table 1). The

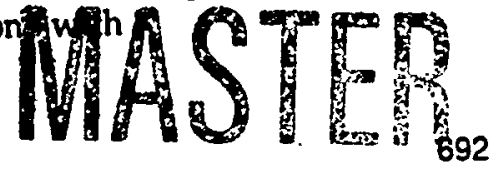




\section{DISCLAIMER}

Portions of this document may be illegible in electronic image products. Images are produced from the best available original document. 


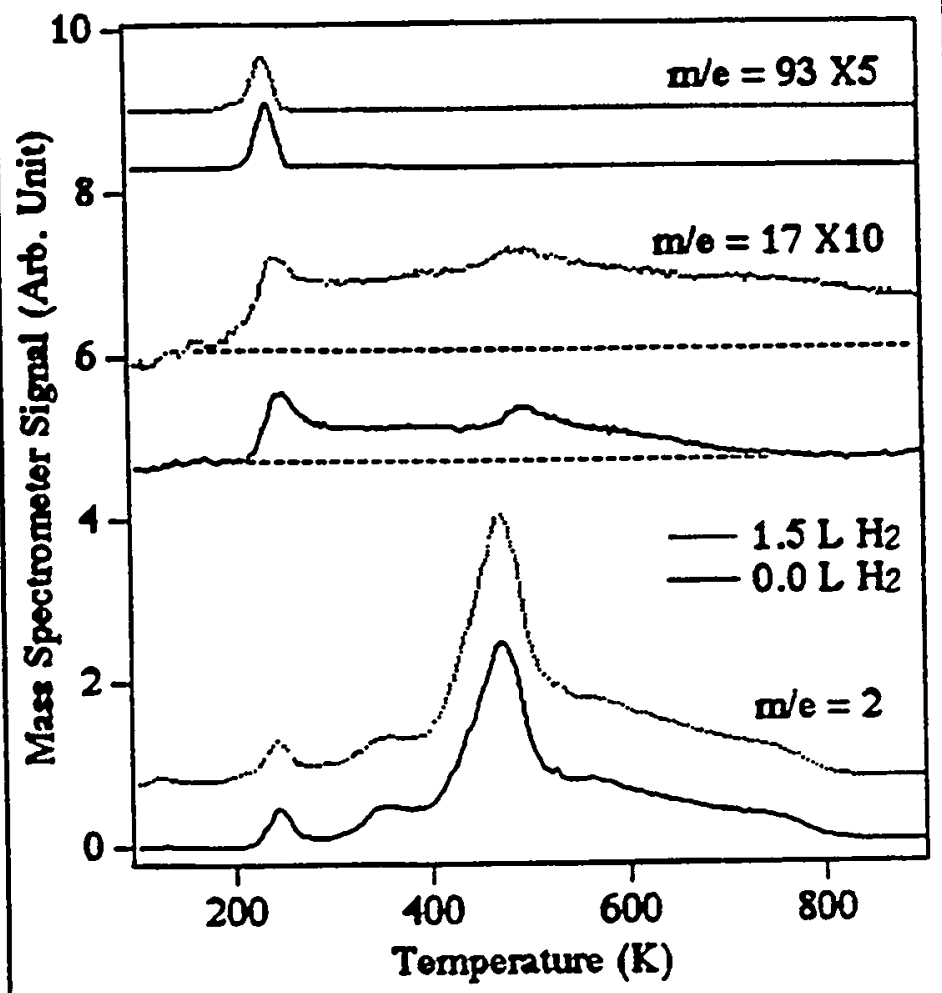

Figure 1. TPD spectra of aniline on PI(111) for an initial coverage of 11 ML. Shown here are the spectra with and without the postadsorbed hydrogen, respectively.

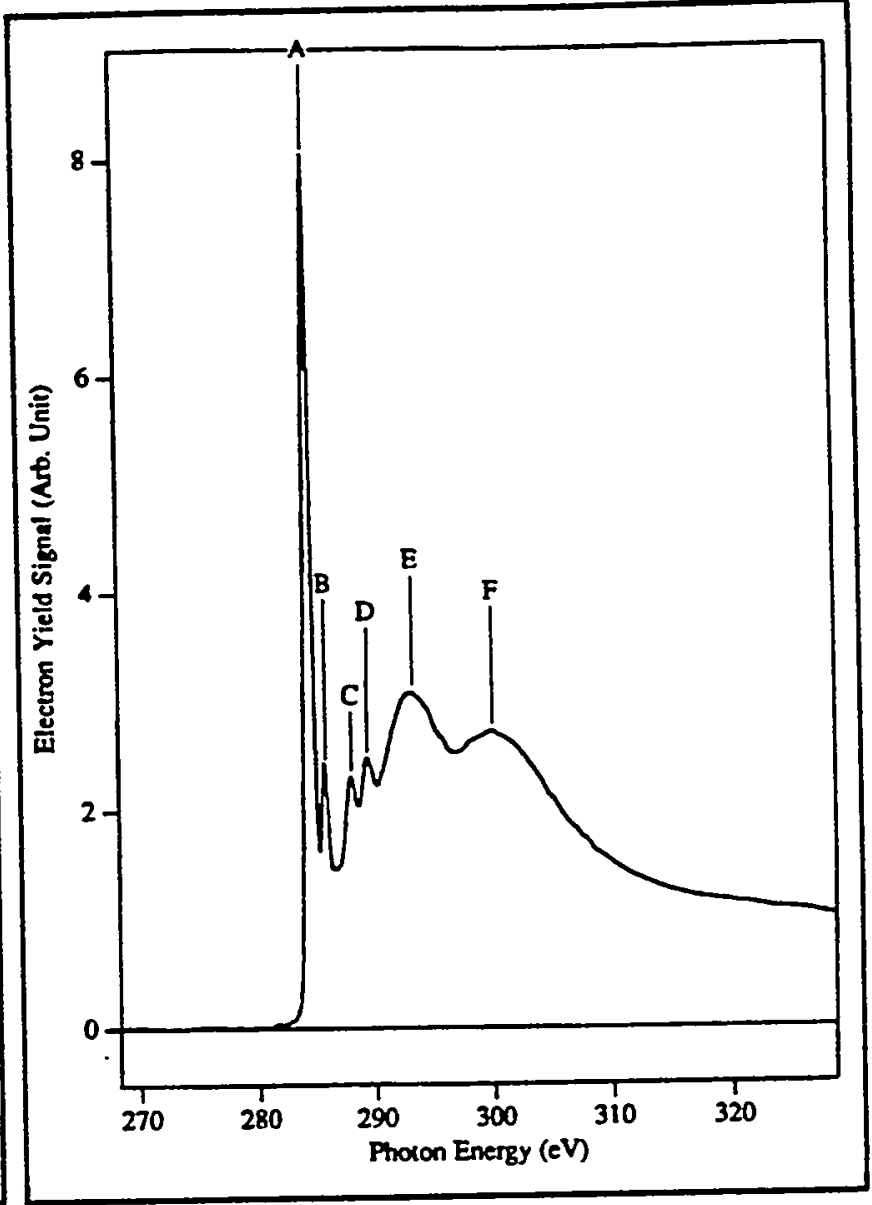

Figure 2. Carbon Kodge NEXAFS spectra for aniline on the PL(111) surface. The resonance assignment is discussed below, and listed in Table 1. spectra of multilayer aniline and multilayer benzene on $\mathrm{Pt}(111)$ contain many similar resonances (5). Additional resonances are observed for the aniline case because the $-\mathrm{NH}_{2}$ group lifts the degeneracy of several molecular orbitals in the aromatic ring. The magnitude of splitting ( $1.3 \mathrm{eV}$ for $\pi 1,2^{*}$ peak) is a direct result of the binding energy shift of the $C$ atom bonded to nitrogen from the rest of the $C$ atoms in the phenyl ring. The $\pi^{*}$ resonances at $288.0 \mathrm{cV}$ and $289.4 \mathrm{eV}$ overlapped in energy with a $\sigma^{*}(\mathrm{C}-\mathrm{H})$ resonance (6). These resonance assignments are in good agreement with those for aniline on the $\mathrm{Ag}(110)$ surface (7).

The assignment of the resonances for the aniline monolayer spectra are directly derived from the multilayer spectra above. For monolayer aniline annealed to $370 \mathrm{~K}$, the ring is oriented almost parallel $\left(<31^{\circ}\right)$ to the $\mathrm{Pt}(111)$ surface (Figure 3). The orientation turns the p-lobes in the aromatic $\pi$ system toward the surface, suggesting $\pi$-bonding of the ring with the surface. The strong nitrogen-metal bond may be the cause of the $30^{\circ}$ tilt of aniline away from the surface. At normal incidence, a strong resonance at $291.4 \mathrm{eV}$ is observed and attributed toa $\sigma$ shape-resonance due to the $C-N$ bond. We made this assignment by comparing with NEXAFS spectra for a variety of pure aromatic hydrocarbons on $\mathrm{Pt}(111)$, which do not have $\sigma C-N^{*}(5)$, and with species which have $\sigma C-N^{*}(8)$. Using dipole selection rules, the spectra indicate that the $C$ $\mathrm{N}$ bond is almost parallel to the $\mathrm{Pt}(111)$ surface at $370 \mathrm{~K}$. A parallel $\mathrm{C}-\mathrm{N}$ bond may activate the $\mathrm{C}-\mathrm{N}$ bond by facilitating the $\pi^{*}$ orbital overlap with metal d orbital. Since benzene from aniline hydrogenolysis desorbs at $400 \mathrm{~K}$, the adsorbed intermediate species at $370 \mathrm{~K}$ are believed to be the primary intermediates for $\mathrm{C}-\mathrm{N}$ bond activation. These spectroscopic results indicate that this intermediate species is bonded to the surface through both the phenyl $\pi$ electrons as well as nitrogen lone pair.

Annealing a monolayer of aniline on $\mathrm{PH} 111$ ) in 0.001 Torr of hydrogen flow gives an NEXAFS spectrum (Figure 3) significantly different from that in vacuum. The $\pi_{1}{ }^{*}\left(C_{2,3,4}\right)$ resonance is shifted by $0.2 \mathrm{eV}$ to $284.2 \mathrm{eV}$ from that at multilayer coverage. This downward shift is believed to be an indication of new bonding between platinum and $C_{2}, C_{3}, C_{4}$ on the phenyl ring (9). The most noticeable spectral changes are the larger $\sigma^{*}$ to $\pi^{*}$ resonance ratio at both normal and grazing incidence compared to those observed in vacuum. The substantial change in $\sigma^{*}$ intensity indicates a loss of aromatic character. We suggest that this may be the result of partial 

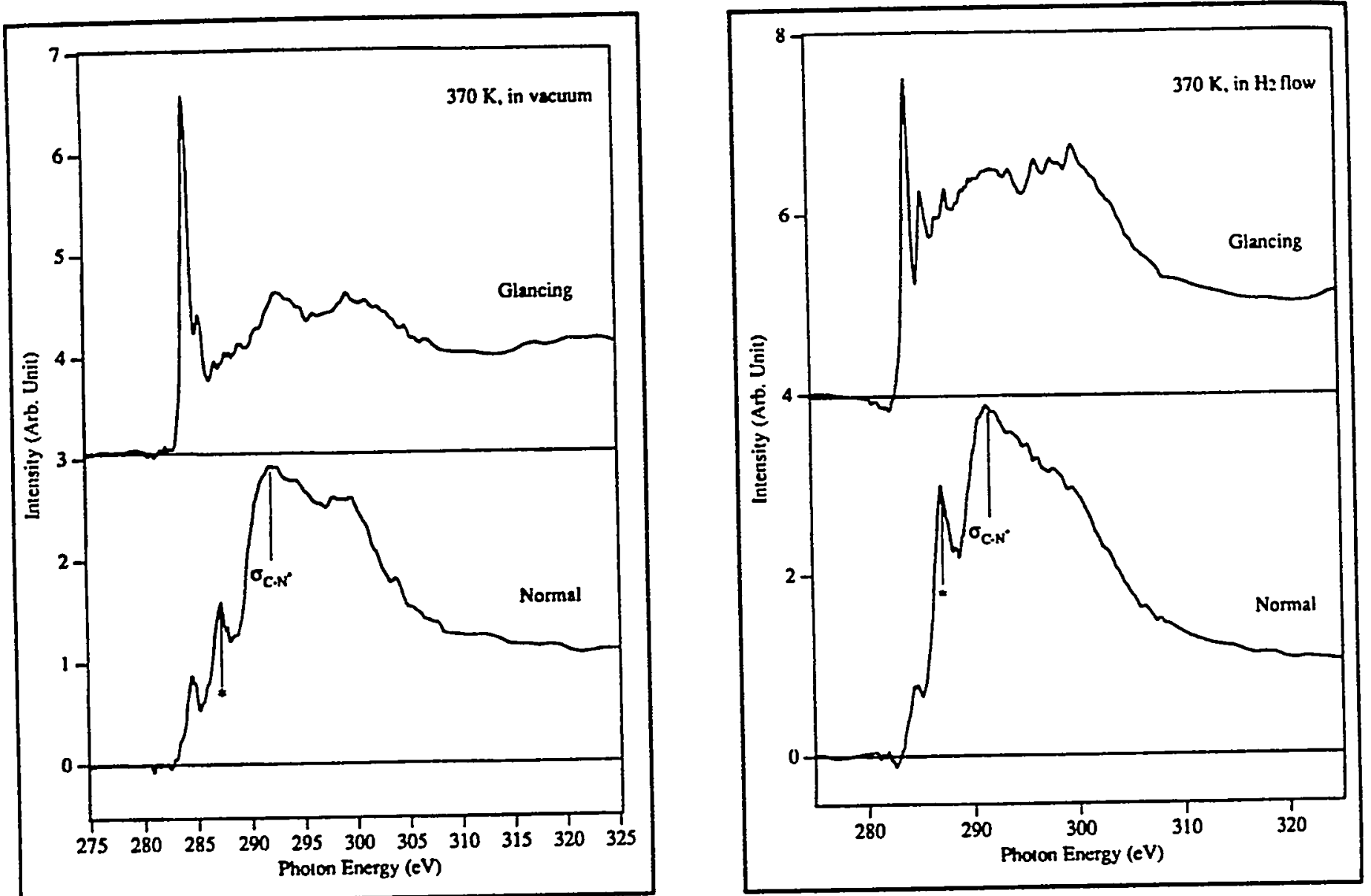

Figura ariline $10370 \mathrm{~K}$ briefly, and quenching down $10100 \mathrm{~K}$. The resonance (") at $287.4 \mathrm{eV}$ arises from carbon monoxide contaminant adsorbed when sites are left by desorting aniline during annealing.

hydrogenation of the aromatic ring at this temperature in flowing hydrogen. Also noticeable is a stronger and broadened $\pi 2^{*}\left(C_{1}\right)$ resonance at 285.7 $\mathrm{eV}$ for the aromatic carbon atom bonded to the nitrogen atom. The peak broadening indicates stronger molecule-surface interactions caused by hybridization of benzene $\pi^{*}$ orbitals with metal states and/or reduced lifetime of $\pi^{*}$ state due to delocalization (5). Further observation reveals that $\sigma \mathrm{C}-\mathrm{N}^{\star}$ resonance becomes more dominant at normal incidence, possible only when C-N bond is parallel to the surface. We believe that this configuration is critical for activating the $\mathrm{C}-\mathrm{N}$ bond and promoting hydrogen addition to the ends of the $\mathrm{C}-\mathrm{N}$ bond.

\section{CONCLUSION}

In conclusion, $\mathrm{C}-\mathrm{N}$ bond activation is substantially enhanced in the presence of hydrogen. After annealing to $370 \mathrm{~K}$, the adsorbed aniline is

Table 1.

NEXAFS Resonance Assignment of Multilayer Aniline/Pt(111)

\begin{tabular}{|c|c|c|c|c|c|c|}
\hline 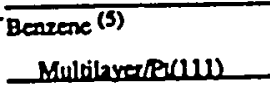 & $\begin{array}{l}x_{12^{\circ}}\left(e_{2}\right) \\
285.0\end{array}$ & $\begin{array}{l}73^{\circ}\left(b_{21}\right) \\
288.9\end{array}$ & $\begin{array}{l}\sigma_{1}{ }^{*}\left(e_{22}\right) \\
2033\end{array}$ & $\begin{array}{l}O_{2}^{\circ}\left(e^{\circ}{ }_{2} \mathrm{O}_{28}\right) \\
300.1\end{array}$ & & \\
\hline Aniline & $\bar{A}$ & $\bar{B}$ & $\bar{C}$ & $\bar{D}$ & $\bar{E}$ & $\overline{\mathbf{F}}$ \\
\hline Mulülayea/AB(110)(n & 285.6 & 287.0 & 209.2 & 290.7 & 295.1 & 302 \\
\hline MulcilayarPu(111) & 284.4 & 285.7 & 288.0 & 289.4 & 293.1 & 300 \\
\hline Ascigrnent & $\begin{array}{l}\pi_{1}^{*}\left(C_{2,3}\right)+ \\
\pi_{2}^{*}\left(C_{2,3,4}\right)\end{array}$ & $\pi_{2}^{*}\left(C_{1}\right)$ & $\begin{array}{l}x_{3}^{*}\left(C_{2,3,4}\right) \\
\text { or CH* }\end{array}$ & $\begin{array}{l}x^{\circ}\left(\mathrm{C}_{1}\right) \\
\mathrm{OCOH}^{*}\end{array}$ & $\sigma_{1} *$ & $\sigma_{2} *$ \\
\hline
\end{tabular}

oriented with the $\mathrm{C}-\mathrm{N}$ bond almost parallel to the $\mathrm{Pt}(111)$ surface. This configuration is believed to facilitate the activation of the $\mathrm{C}-\mathrm{N}$ bond, especially in the presence of surface hydrogen. When the surface hydrogen supply is sufficiently high, hydrogenolysis will be favored over competing surface processes like dehydrogenation and decomposition.

\section{ACKNOWLEDGMENTS}

Financial support for this work was provided by the Office of Basic Encrgy Sciences, the Department of Energy (Grant no. DE-FGO2-91ER14190).

\section{LTERATURE CITED}

(1) Gland, J. L. and Somorjai, G. A., Adv. Coll. Interface Sc., 5, 205 (1976). 
(2) a) Schoofs, G. R. and Benziger, J. B., J. Phys. Chem., 22,741 (1988);

b) Myers, A. K. and Benziger, J. B., Langmuir, 5, 1270 (1989).

(3) a) Shen S., Zaera, F., Fischer, D. A. and Gland, J. L., J. Chem. Phys., 89,590 (1988); b) Fischer, D. A., Colbert, J. and Gland, J. L., Rev. Sci. Instrum., 60, 1596 (1989).
(5) Horsley, J.A., Stöhr, J., Hitchcock, A. P., Newbury, D. C., Johnson, A. L., Sette, F., J. Chem. Phys., 83,6099 (1985).

(6) Stöhr, J., Outka, D. A., Baberschke, K., Arvanitis, D. and Horsley, J. A., Phys.Rev., B36, 2976 (1987).

(7) Solomon, J. L., Madix, R. J. and Stöhr, J., Surf. Science, 255, 12 (1991).
(8) Sodhi, R. N S. and Brion, C. E., J. Electron Spectrosc. Relat. Phenom., 36, 187 (1985).

(9) Koesmer, T. J., Stöhr, J., Gland, J. L. and Horsley, J. A., Chem. Phys. Lett., 105, 332 (1984).

\title{
DISCLAIMER
}

\begin{abstract}
This report was prepared as an account of work sponsored by an agency of the United States
Government. Neither the United States Government nor any agency theref nor any of their employees, makes any warranty, express or implied, or assumes any thereof, nor any of their bility for the accuracy, completeness, or usefulness of any infor any legal liability or responsiprocess disclosed, or represents that its use would not infinformation, apparatus, product, or ence herein to any specific commercial product, process, or service brivaty owned rights. Refermanufacturer, or otherwise does not necessarily constitute or ice by trade name, trademark, mendation, or favoring by the United States Government or imply its endorsement, recomand opinions of authors expressed herein do Government or any agency thereof. The views United States Government or any agency thereof.
\end{abstract}

